\title{
A Compact and High Efficiency Intracavity Opo Based on Periodically-poled Lithium Niobate
}

\section{Ke Wang ( $\nabla$ wangke_work@foxmail.com )}

National Laboratory of Solid State Microstructures, School of Physics, School of Electronic Science and Engineering, College of Engineering and Applied Science, and Collaborative Innovation Center of Advanced Microstructures, Nanjing University, Nanjing 210093, China

\section{Mingyao Gao}

Nanjing University

\section{Shuhui Yu}

Nangjing Star-shining Technology Company Limited

Jian Ning

Nangjing Star-shining Technology Company Limited

\section{Zhenda Xie}

Nanjing University

\section{Xinjie Lv}

Nanjing University

Gang Zhao

Nanjing University

\section{Shining Zhu}

Nanjing University

\section{Research Article}

Keywords: continuous-wave, mid-infrared, intracavity optical parametric oscillator, periodically poled lithium niobate crystal, tunable

Posted Date: December 31st, 2020

DOl: https://doi.org/10.21203/rs.3.rs-133980/v1

License: (c) (i) This work is licensed under a Creative Commons Attribution 4.0 International License. Read Full License

Version of Record: A version of this preprint was published at Scientific Reports on March 3rd, 2021. See the published version at https://doi.org/10.1038/s41598-021-84721-9. 



\title{
A compact and high efficiency intracavity OPO based on periodically-poled lithium niobate
}

\author{
$\mathrm{Ke} \mathrm{Wang}^{1^{\star}}$, Mingyao Gao ${ }^{1}$, Shuhui $\mathrm{Yu}^{2}$, Jian Ning ${ }^{2}$, Zhenda Xie ${ }^{1,2}$, \\ Xinjie Lv ${ }^{1,2}$ * , Gang Zhao ${ }^{1,2}$ \& Shining Zhu', 2 \\ ${ }^{I}$ National Laboratory of Solid State Microstructures, School of Physics, School of Electronic Science and \\ Engineering, College of Engineering and Applied Science, and Collaborative Innovation Center of Advanced \\ Microstructures, Nanjing University, Nanjing 210093, China
}

${ }^{2}$ Nangjing Star-shining Technology Company Limited, Nanjing 210043, China

*Ke Wang, E-mail:wangke_work@foxmail.com; *XinjieLLv,E-mail: lvxinjie@nju.edu.cn

Abstract: We demonstrate a compact, high-efficiency and widely tunable intracavity singly resonant optical parametric oscillator (IC-OPO) based on multichannel periodically-poled lithium niobate (PPLN). The IC-OPO is composed of $808 \mathrm{~nm}$ pump laser diode (LD), Nd: $\mathrm{YVO}_{4}$ laser and linear OPO. The continuous-wave (CW) mid-infrared (MIR) output laser is tunable from $2.25 \mu \mathrm{m}$ to $4.79 \mu \mathrm{m}$. The maximum output power exceeds $1.08 \mathrm{~W}$ at $3.189 \mu \mathrm{m}$ at $9.1 \mathrm{~W} \mathrm{LD}$ pump power and the conversion efficiency is $11.88 \%$. We also build up a prototype with volume of $145 \times 85 \times 42.5 \quad \mathrm{~mm}^{3}$ and its total weight is less than $2 \mathrm{Kg}$. The measured power stability is $1.3 \%$ Root Meat Square (RMS) for a $3 \mathrm{~h}$ duration under simulated high temperature conditions of $40{ }^{\circ} \mathrm{C}$. RMS is $2.6 \%$ for a $4 \mathrm{~h}$ duration when simulated temperature is $-40{ }^{\circ} \mathrm{C}$.

Keywords: continuous-wave, mid-infrared, intracavity optical parametric oscillator, periodically poled lithium niobate crystal, tunable.

\section{Introduction}

With recent progress in the fabrication of periodically-poled ferroelectric materials, quasi-phase-matching (QPM) technique is growing rapidly, which can be used in optical parametric oscillator (OPO) [Error! Reference source not found.,2]. In nonlinear optics, $\mathrm{LiNBO}_{3}$ is one of important crystals with large nonlinear coefficient $\left(\mathrm{d}_{33} \sim 27 \mathrm{pm} / \mathrm{v}\right)$ [3], especially in widely tunable MIR OPO. MIR is the atmospheric window, which means it's good for remote sensing through air [4]. Meanwhile, absorption of many industrial polluted gas peaks at 2-5 $\mu \mathrm{m}$ such as $\mathrm{CH}_{4}, \mathrm{C}_{3} \mathrm{H}_{8}, \mathrm{HCl}, \mathrm{HF}$ and so on. MIR laser can serve as an exhaust emission detector [5]. In addition, MIR laser is widely applied in martial and medical field. It's important to produce compact and high quality (high-efficiency and widely-tunable) MIR laser. A number of mid-infrared continuous waves based on IC-OPO have been reported [6-12]: Carleton et al reported a CW IC-OPO based on $\mathrm{PPRbTiOAsO}_{4}$ pumped by $1064 \mathrm{~nm}$ $\mathrm{Nd}: \mathrm{YVO}_{4}$ laser. At $3 \mathrm{~W}$ of input diode-laser, the maximum power of $65 \mathrm{~mW}$ of idler at $3.52 \mu \mathrm{m}$ was obtained, which corresponds to an optical-to-optical conversion of efficiency of $2.17 \%$ [6]. In 2008, an IC-OPO based on PPLN pumped by $1064 \mathrm{~nm}$ Nd: $\mathrm{YVO}_{4}$ laser was described, whose conversion efficiency was $1.82 \%$ from $808 \mathrm{~nm}$ to $3.86 \mu \mathrm{m}$ [8]. A CW singly-resonant IC-OPO based on a Yb :KYW laser had conversion efficiency of $4.08 \%$ at $\sim 3500 \mathrm{~nm}$ [11]. In 2017, Haiyong Zhu demonstrated a CW singly resonate IC-OPO based on PPLN pumped by a diode-pumped Nd: $\mathrm{YVO}_{4}$ laser at $1064 \mathrm{~nm}$. The conversion efficiency was $10.2 \%$ with tunable span from 2.95 $\mu \mathrm{m}$

to $4.16 \mu \mathrm{m}$ [12]. However, most OPOs are built on optical tables which are not portable. Thus, it's difficult for them to be practically used in moving vehicles based on the air, land or water [13-15]. Yichen Liu reported a CW OPO module, not including pump, with volume of $220 \times 60 \times 55 \mathrm{~mm}^{3}$ in 2018 , which covered a tuning range of 2.42-2.93 $\mu \mathrm{m}$ and 3.14- $3.45 \mu \mathrm{m}$ [16].

In this paper, we report a singly resonate IC-OPO based on multichannel PPLN. The OPO is pumped by a 1064 $\mathrm{nm}$ Nd:YVO 4 laser, with a nested cavity configuration. The schematic of the IC-OPO is shown in Fig. 1. The 1064 $\mathrm{nm}$ laser cavity was formed by the front face of $\mathrm{Nd}: \mathrm{YVO}_{4}$ crystal and the output mirror of $\mathrm{OPO}$, and the $\mathrm{Nd}: \mathrm{YVO}_{4}$ crystal was pumped by $808 \mathrm{~nm} \mathrm{LD}$ from the front face. The input mirror of OPO was in the laser cavity and followed by a multichannel PPLN. The output laser was filtered by two dichroic mirrors, which were transparent to MIR and reflect $808 \mathrm{~nm}, 1064 \mathrm{~nm}$ and near-infrared. The scale of total set-up was $120 \mathrm{~mm}$ in length from LD to the output window of OPO. At LD power of $9.1 \mathrm{~W}$, the IC-OPO generated $1.08 \mathrm{~W}$ of the maximum idler power at $3.189 \mu \mathrm{m}$, indicating conversion efficiency of $11.88 \%$ from LD to mid-infrared. By changing channels and 
temperature of PPLN, the output mid-infrared of IC-OPO was continuously tunable from $2.25 \mu \mathrm{m}$ to $4.794 \mu \mathrm{m}$. A compact prototype was also fabricated with dimension of $145 \times 85 \times 42.5 \mathrm{~mm}^{3}$ and the weight of less than $2 \mathrm{Kg}$. The power stability was measured to be below $3 \% \mathrm{RMS}$ tested at the environmental temperature of $40{ }^{\circ} \mathrm{C}$ and $-40{ }^{\circ} \mathrm{C}$.

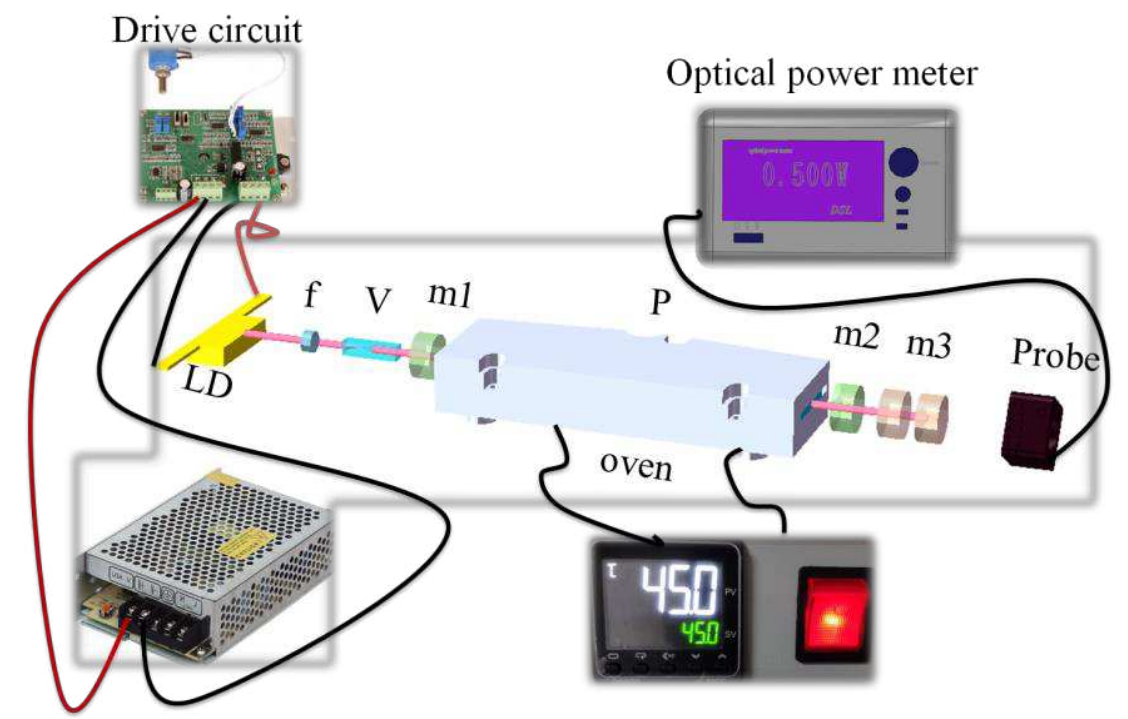

Switching power supply

Temperature controller

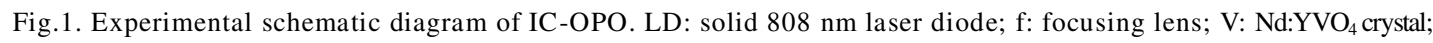

m1: IC-OPO input mirror; P: PPLN crystal; m2: IC-OPO output mirror; m3: dichroic mirrors.

\section{Methods}

Detailed illustration of experimental set-up. The highest power of LD (Focus Light) was $10 \mathrm{~W}$, whose output theoretically peaked at $808 \mathrm{~nm}$ when its operating temperature was at $25^{\circ} \mathrm{C}-30{ }^{\circ} \mathrm{C}$. The thermal effects could not be ignored when LD pump power was rising. $\mathrm{LD}$ was fixed in a water-cooled copper heat sink to relieve the thermal effects. And the refrigerant water had been maintained at the temperature of $25{ }^{\circ} \mathrm{C}$ throughout the experiment.

The front face of $\mathrm{Nd}: \mathrm{YVO}_{4}$ crystal (CASTECH) was HR coated at $1064 \mathrm{~nm}$ and AR coated at $808 \mathrm{~nm}$ which served as a $1064 \mathrm{~nm}$ resonant mirror. Meanwhile IC-OPO output mirror was HR coated at $1064 \mathrm{~nm}$ and 1.3-1.8 $\mu \mathrm{m}$ on concave face $(\mathrm{R}=-100 \mathrm{~mm})$, HT coated at 2.6-4.1 $\mu \mathrm{m}$ on both sides. These two mirrors formed $1064 \mathrm{~nm}$ laser cavity. IC-OPO input mirror was HR coated at 1.4-1.7 $\mu \mathrm{m}$ and HR coated at 2.6-4.1 $\mu \mathrm{m}$, AR coated at 1064 $\mathrm{nm}$. Focusing lens owned the focal distance of $4.5 \mathrm{~mm}$.

The Nd: $\mathrm{YVO}_{4}$ crystal wrapped by indium foil and mounted tightly in a water-cooled copper heat sink was 2 $\mathrm{mm} \times 2 \mathrm{~mm} \times 8 \mathrm{~mm}$ in size cooled by refrigerant water. The OPO crystal was 5-mol \% MgO:PPLN (CTL Photonics) and was $50 \mathrm{~mm}$ long with an aperture of $10 \mathrm{~mm} \times 1 \mathrm{~mm}$. The crystal contained ten grating periods of 27.6-31.6 $\mu \mathrm{m}$ as a nonlinear material in the set-up. PPLN was AR coated at 1.064 $\mu \mathrm{m}, 1.4-1.7 \mu \mathrm{m}$ and 2.6-4.4 $\mu \mathrm{m}$ on both sides. The OPO resonator cavity was packaged in an oven, which was conveniently used to adjust and control the PPLN operating temperature [17]. In addition, this oven was fixed in a three-dimensional adjustment table, used to change channels. The transmittance of IC-OPO input mirror was of $97 \%$ at $1064 \mathrm{~nm}$ and $0.46 \%-0.058 \%$ at signal wave $(1500-1700 \mathrm{~nm})$. As for IC-OPO output mirror, its transmittance was of $0.17 \%$ at $1064 \mathrm{~nm}$ and $0.076 \%-0.13 \%$ at signal wave $(1400-1700 \mathrm{~nm})$. The two mirrors were separated by $55 \mathrm{~mm}$ for linear cavity.

Results of IC-OPO based on PPLN. We put IC-OPO input mirror and PPLN in laser cavity and adjusted operating temperature as well as channels. Through spectrometer with range of $1200 \mathrm{~nm}-2400 \mathrm{~nm}$ (AQ6375B, YOKOGAWA), wide span of signal light spectra was acquired, which was from $1.40 \mu \mathrm{m}$ to $1.67 \mu \mathrm{m}$ at PPLN operating temperature of $40{ }^{\circ} \mathrm{C}$ when $\mathrm{LD}$ pump power was $4.84 \mathrm{~W}$. Except for wavelength, we also measured power of different idler output while changing the channel of PPLN. The different points mean the power of idler shown in Fig. 2. 


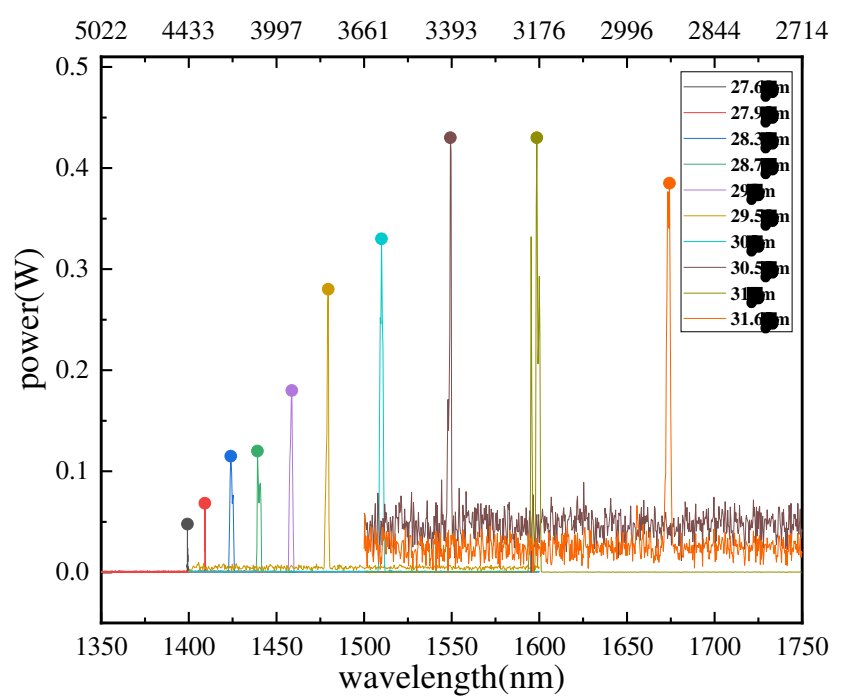

Fig.2. Signal wavelength of different channels at operating temperature of $40^{\circ} \mathrm{C}$. Label of bottom axis means wavelength of signal while top line is corresponding calculated wavelength of idler and the $\mathrm{Y}$-axis is power of idler.

According to energy conversion equation in a general three-wave interaction, the idler wavelength can be calculated as

$$
\frac{1}{\lambda_{p}}=\frac{1}{\lambda_{s}}+\frac{1}{\lambda_{i}},
$$

where $\lambda_{p}, \lambda_{s}, \lambda_{i}$ are the pump, the signal and the idler vacuum wavelength, respectively [18]. Therefore, idler wavelength spans from $2.92 \mu \mathrm{m}$ to $4.44 \mu \mathrm{m}$ at operating temperature of $40{ }^{\circ} \mathrm{C}$.

We increased power from $5 \mathrm{~mW}$ to $9.1 \mathrm{~W}$ controlling PPLN operating temperature at $40{ }^{\circ} \mathrm{C}$. As for $31 \mu \mathrm{m}$, its threshold was found to be $680 \mathrm{~mW}$. When LD pump power was $9.1 \mathrm{~W}$, high power of idler was measured, which was $1.012 \mathrm{~W}$. Efficiency and output power were shown in Fig.3. The power of rest periods or same period at higher temperature was a little lower. The highest conversion efficiency of $808 \mathrm{~nm}$ transferring to idler is $11.88 \%$ at $3189 \mathrm{~nm}$.

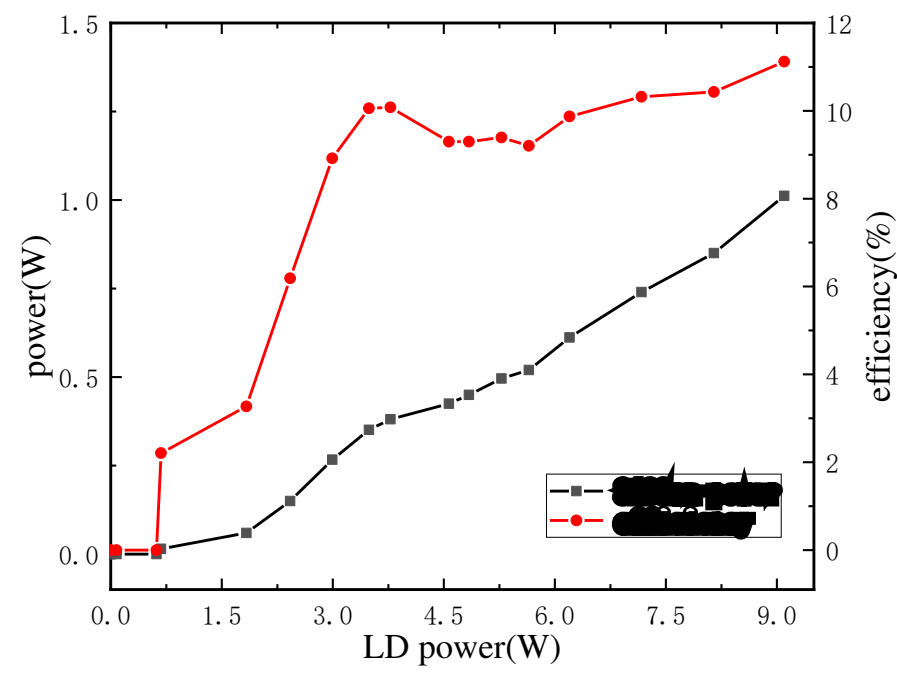

Fig.3. Output power and efficiency versus incident LD power.

To broaden the range of MIR output, we tried another multichannel PPLN with 6 shorter grating periods owning dimensions of $33.8 \mathrm{~mm} \times 6 \mathrm{~mm} \times 1 \mathrm{~mm}$ and new cavity mirror with wider range of coating film. New IC-OPO output mirror is HR coated at $1064 \mathrm{~nm}, 1.35-2 \mu \mathrm{m}$ and AR coated at 2.3-5 $\mu \mathrm{m}$. New IC-OPO input mirror is HR coated at 1.35-2 $\mu \mathrm{m}$ and HT coated at 2.3-5 $\mu \mathrm{m}$. Channels of $25.5 \mu \mathrm{m}$ and $26 \mu \mathrm{m}$ didn't generate MIR output shown in Fig.4, because span of 
membrane system coated in OPO cavity has low reflectivity below $1360 \mathrm{~nm}$.

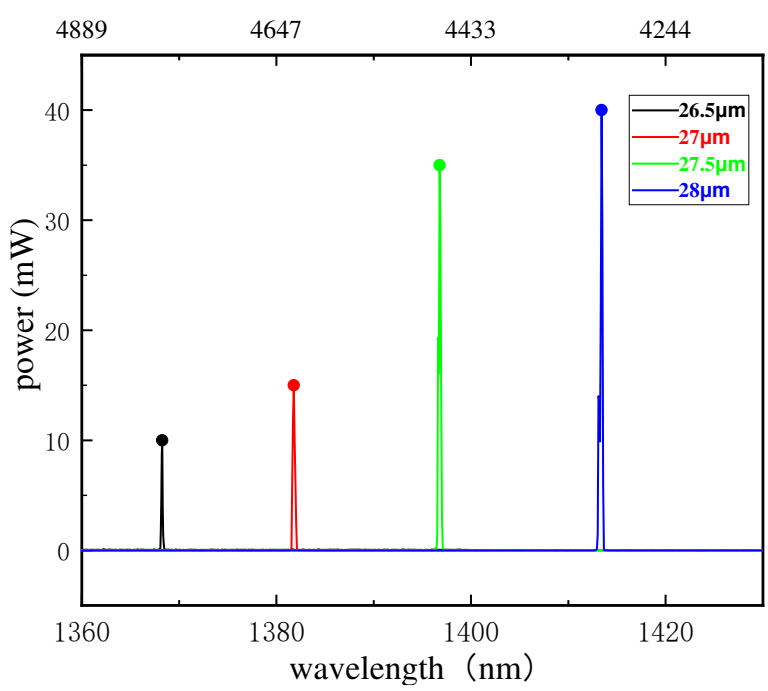

Fig.4. Signal wavelength of different channels at $45^{\circ} \mathrm{C}$ when power is $4.84 \mathrm{~W}$.

We changed temperature from $40{ }^{\circ} \mathrm{C}$ to $200^{\circ} \mathrm{C}$ while tuning period from $26.5 \mu \mathrm{m}$ to $31.6 \mu \mathrm{m}$, measuring wavelength of signal using two multichannel PPLN described above. Wavelength coincided when controlling temperature of adjacent channels shown in Fig.5. For example, signal wavelength was $1682.98 \mathrm{~nm}$ in $31 \mu \mathrm{m}$ at $160{ }^{\circ} \mathrm{C}$ while it's $1674.29 \mathrm{~nm}$ in $31.6 \mu \mathrm{m}$ at $40{ }^{\circ} \mathrm{C}$. At certain temperature signal wavelength would be the same as that in $31.6 \mu \mathrm{m}$ at $40{ }^{\circ} \mathrm{C}$. It's possible to tune output wavelength in a continuous way by varying temperature of crystal or fabricating a crystal with finer grating period increments.

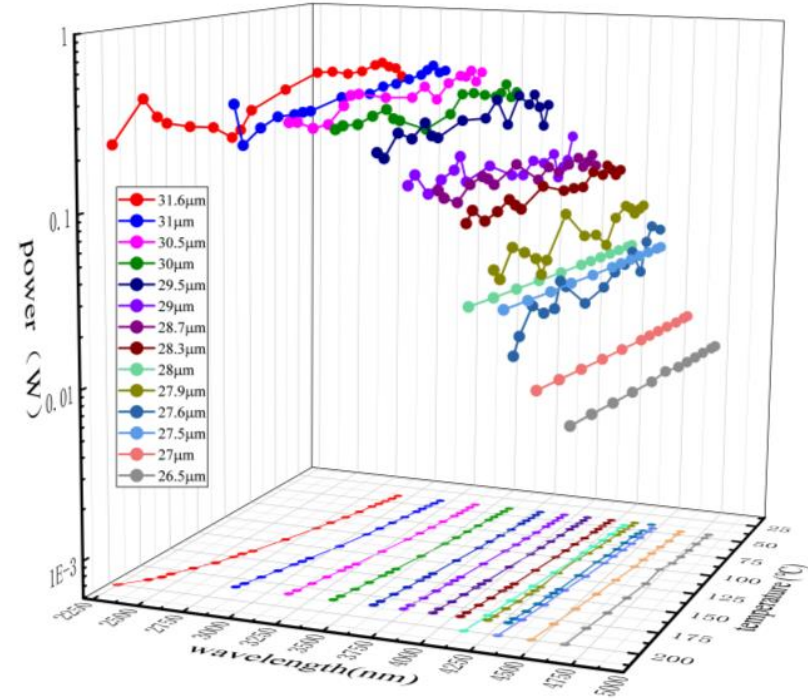

Fig.5. Curves of tuning temperature and periods. Span of idler is from $2.25 \mu \mathrm{m}$ to $4.79 \mu \mathrm{m}$ when pump power is $4.8 \mathrm{~W}$.

We measured the shortest signal wave in $26.5 \mu \mathrm{m}$ at operating temperature of $45{ }^{\circ} \mathrm{C}$ when power of LD was $4.8 \mathrm{~W}$. The output spectrum peaked at $1368 \mathrm{~nm}$ shown in Fig.6. a. Hence, the longest MIR we calculated was $4793.8 \mathrm{~nm}$. However, the power of $4793.8 \mathrm{~nm}$ was very low, which was only $15 \mathrm{~mW}$. From spectrum, we could find there existed multiple longitudinal mode. In addition, there was no phenomena of oscillation in $26 \mu \mathrm{m}$ and $25.5 \mu \mathrm{m}$. Consideration is also given to practical factors that limit the OPO performance such as crystal damage mechanism and limits. Equally, wavelength in 26 $\mu \mathrm{m}$ or $25.5 \mu \mathrm{m}$ is over to edge of $1.35 \mu \mathrm{m}$ HR membrane. We guess that energy loses because of new PPLN-OPO input mirror without being HR coated at range of idler, which would be improved in our subsequent work. 

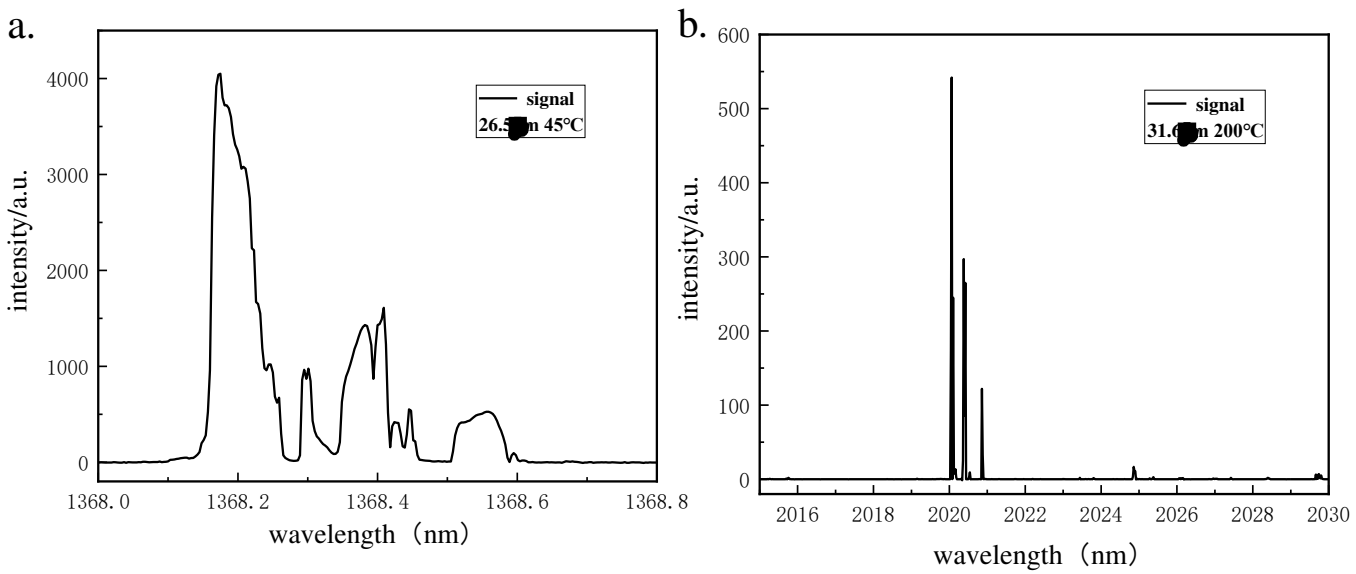

Fig.6. Shortest and longest signal spectra.

In $31.6 \mu \mathrm{m}$, there was no obvious power loss when we changed temperature from $150{ }^{\circ} \mathrm{C}$ to $200{ }^{\circ} \mathrm{C}$ under same condition of pump in $4.8 \mathrm{~W}$. The longest wavelength of signal was obtained which was $2020.058 \mathrm{~nm}$ shown in Fig.6. b. Through calculation, wavelength of idler was $2250.139 \mathrm{~nm}$ with 230 $\mathrm{mW}$. Instead of running on a single axial mode of the OPO resonator, the cavity tended to run multiple axial modes with relatively wide linewidth. To constraint mode hops, etalon would be used follow-up.

Configuration of prototype. Through a series of experiments of IC-OPO, we believed that it was possible to minimize scale of IC-OPO. We designed and assembled the prototype of IC-OPO shown in Fig.7. We adhered optical mirror to the light path plate. It was difficult to control the amount of adhesive precisely which would influence the stability and efficiency of OPO while adhesive was curing. So, conversion efficiency of prototypes is lower than that of principled set-up which was $8.6 \%$ at $3.189 \mu \mathrm{m}$. The tuning range is the same as principled set-up.
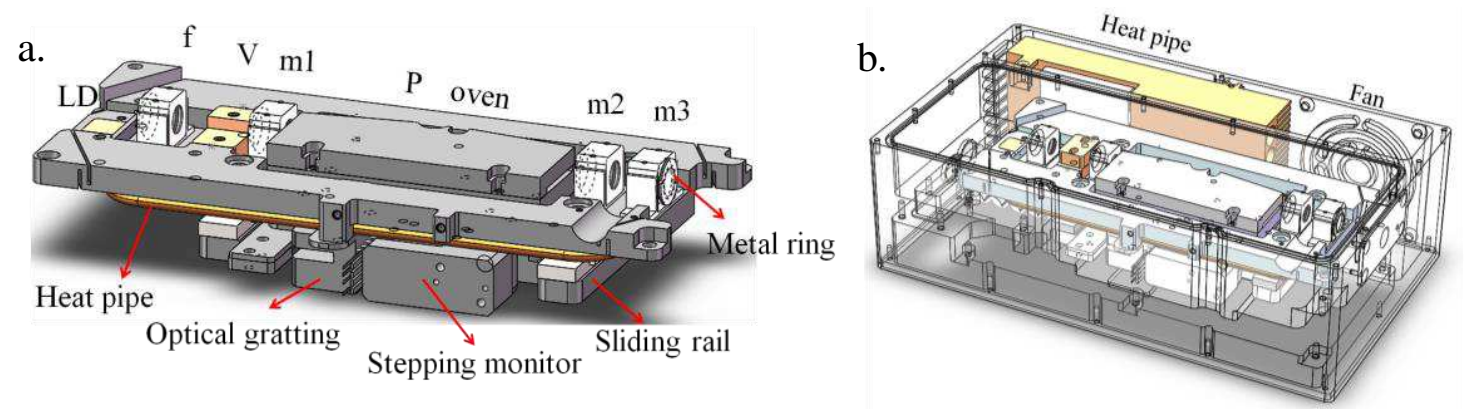

Fig.7. Design of the singly resonant IC-OPO prototype.

The prototype was divided into two parts, optical plate and integrated circuit. All optical components were settled in optical plate which was upward side. The integrated circuit was fixed underneath the optical plate. There was aluminum plate to separate these two parts. The optical plate was made of aluminum for heat conduction while the shell of prototypes was made of steel for rigidity. The shape and structure of optical plate were shown in Fig.7. a. In order to improve the precision of adjustment for different channels, we used optical grating, stepping motor and sliding rail which could realize the function of automatic adjustment. In the prototype, the LD couldn't be fixed in a water-cooled copper heat sink. We used thermo electric cooler (TEC), heat pipe and a fan to dissipate heat and to control the temperature of LD. We also came up with processing small metal rings to fix the cavity mirror. The sample of compact singly resonant IC-OPO was show in Fig. 7. b. Our detailed structure of prototypes is still improving. 

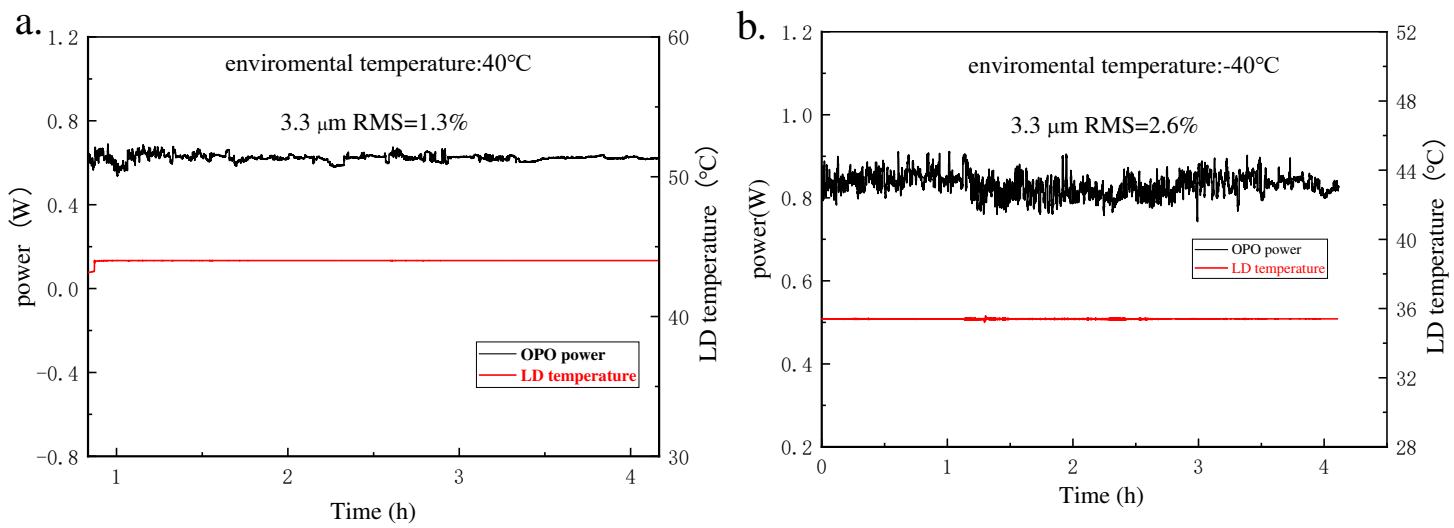

Fig.8. Results of test at low and high temperatures.

\section{Results and discussion}

Our prototype was tested at low and high temperatures while temperature of PPLN was $80{ }^{\circ} \mathrm{C}$ shown in Fig.8. The power of $\mathrm{LD}$ was $10 \mathrm{~W}$ when a prototype was tested. The average power was $0.624 \mathrm{~W}$ when environmental temperature was $40{ }^{\circ} \mathrm{C}$ shown in Fig.8.a. The RMS of the MIR output power in $3 \mathrm{~h}$ was $1.3 \%$. We could tell that the average power was $0.831 \mathrm{~W}$ when environmental temperature was $-40{ }^{\circ} \mathrm{C}$ from Fig.8.b. Although its average power was higher, the RMS of the same MIR output was lower. We could know that as environmental temperature changes, the temperature of LD was different, which influenced output of OPO. The power of MIR output would be higher when the temperature of LD was well controlled at $25{ }^{\circ} \mathrm{C}$. As above mentioned, the MIR output exceeded at $1 \mathrm{~W}$ when the temperature of $\mathrm{LD}$ was at $25{ }^{\circ} \mathrm{C}$. The power was less than $0.8 \mathrm{~W}$ when the temperature of $\mathrm{LD}$ was at $44{ }^{\circ} \mathrm{C}$ while it was over $0.8 \mathrm{~W}$ when the temperature of $\mathrm{LD}$ was about $34{ }^{\circ} \mathrm{C}$. From the results, we could tell that it was more stable when environmental temperature was higher. We guessed that the working temperature of PPLN was more stable when environmental temperature was higher. Our following work will focus on maintaining inside temperature of prototypes to make sure power of OPO is more stable even environmental temperature is changing.

The volume of this prototype is $145 \times 85 \times 42.5 \mathrm{~mm}^{3}$ and its weight is less than $2 \mathrm{~kg}$. So our prototypes are portable. The performance of prototypes maintains stable after vibration and transport by vehicles without delicate protection. As far as we know, our prototypes are at the leading edge when size, tuning range and efficiency are concerned.

\section{Conclusion and outlook}

In summary, we have presented a compact and widely-continuously tunable MIR singly resonant IC-OPO based on PPLN with multiple grating structures by the means of QPM technique. A spectral tunability from 2.25-4.79 $\mu \mathrm{m}$ is demonstrated in the $\mathrm{CW}$ region. High power and low threshold are achieved. Conversion efficiency is approximate to $12 \%$. After manufacturing suitable HR mirror and PPLN with specific period, our prototypes are under configuration with good performance. The volume of our prototype is $145 \times 85 \times 42.5 \mathrm{~mm}^{3}$ which weighs less than $2 \mathrm{Kg}$. Through the test at high and low temperature, the power stability at $3.3 \mu \mathrm{m}$ is measured to be less than $3 \%$ RMS. We believe that such a compact, high-efficiency, tunable, stable OPO prototype can be widely used. It has high potential for practical applications.

From the spectrum of the signal, it was obvious that our singly IC-OPO oscillated in a multiple longitudinal mode. More work was needed to be done to narrow the linewidth of IC-OPO. For example, we could insert Perot-Fabry etalon to constrain the linewidth of $1064 \mathrm{~nm}$ and MIR. The design of our prototype made it possible to minimize portable IC-OPO without losing its function. When single longitudinal mode was acquired, our prototypes would be more practical.

\section{Data availability}

The data that support the findings of this study are available from the corresponding author upon reasonable request. 


\section{Reference}

1. Myers, L. E. \& Bosenberg, W. R. Periodically poled lithium niobate and quasi-phase-matched optical parametric oscillators. IEEE Journal of Quantum Electronics. 33, 1663-1672 (1997).

2. Dunn, M. H. \& Ebrahimzadeh, M. Parametric generation of tunable light from continuous-wave to femtosecond pulses. Science. 286, 1513-1517 (1999).

3. Byer, R. L., Herbst, R. L., Feigelson, R. S. \& Kway, W. L. Growth and application of LiNbO 3. Opt. Comm. 12, 427-429 (1974)

4. Numata, K. et al. Ground demonstration of trace gas lidar based on optical parametric amplifier. Journal of Applied Remote Sensing. 6, 063561 (2012).

5. Moulton, P. F., Dergachev, A., Isyanova, Y., Pati, B. \& Rines, G. Recent advances in solid state lasers and nonlinear optics for remote sensing. Lidar Remote Sensing for Industry and Environment Monitoring III. International Society for Optics and Photonics. 4893, 193 (2003).

6. Carleton, A., Stothard, D. J. M., Lindsay, I. D., Ebrahimzadeh, M. \& Dunn, M. H. Compact, continuous-wave, singly resonant optical parametric oscillator based on periodically poled $\mathrm{RbTiOAsO}_{4}$ in a Nd:YVO 4 laser. Opt. Lett. 28, 555-557 (2003).

7. Abitan, H. \& Buchhave, P. Continuous-wave singly resonant optical parametric oscillator placed inside a ring laser. Appl. Opt. 42, 6630-6635 (2003).

8. Ding, X. et al. Continuous-wave mid-infrared intracavity singly resonant optical parametric oscillator based on periodically poled lithium niobate. Chin. Phys. B. 17, 211 (2008).

9. Boyko, A. A. et al. Optical parametric oscillator pumped at $1 \mu \mathrm{m}$ with intracavity mid-IR difference-frequency generation in OPGaAs. Opt. Mater. Exp. 8, 549-554 (2018).

10. Morozov, Y. A. Transient power characteristics of a compact singly resonant intracavity optical parametric oscillator pumped by a semiconductor disk laser. JOSA B. 33, 1470-1475 (2016).

11. Ding, Z. W., Liu, P., Li Y. \& Zhang, Z. W. Continuous-wave, singly-resonant, intracavity optical parametric oscillator based on a single-mode-laser-diode-pumped Yb: KYW laser. Opt. Lett. 43, 2807-2810 (2018).

12. Zhang, J. et al. Mid-infrared tunable intracavity singly resonant optical parametric oscillator based on MgO:PPLN. International Journal of Optics. 2017, 3610162 (2017).

13. Bosenberg, W. R. $93 \%$ pump depletion, $3.5 \mathrm{~W}$ continuous-wave, singly resonant optical parametric oscillator. Opt. Lett. 21, 1336-1338 (1996)

14. Vainio, M. Singly resonant cw OPO with simple wavelength tuning. Opt. Exp. 16, 11141-11146 (2008).

15. Ricciardi, I. A narrow-linewidth optical parametric oscillator for mid-infrared high-resolution spectroscopy. Mol. Phys. 110, 2103-2109 (2012).

16. Liu, Y. C. et al. A high-power continuous-wave mid-infrared optical parametric oscillator module. Appl. Sci. 8, 1 (2018)

17. Li, X. J., Zhang, B. G., Yao, J. Q. \& Zhang, J. F. Infrared OPO temperature tuning based on periodically-poled lithium niobate. Chin. Opt. Lett. 1, 711-713 (2003).

18. Yamada, M., Nada, N., Saitoh, M. \& Watanabe, K. First-order quasi-phase matched $\mathrm{LiNbO}_{3}$ waveguide periodically poled by applying an external field for efficient blue second-harmonic generation. Appl. Phys. Lett. 62, 435-436 (1993). 


\section{Acknowledgement}

The authors thank Yuqing Zhang for his amending advice and acknowledge stimulating discussion with Jinlong Xu.

\section{Author contributions}

K. W., M. Y. G. and S. H. Y. fabricated the prototype; K. W. and M. Y. G measured the spectrum and power of IC-OPO; K. W., S. H. Y. and J. N. conceived the structure of the prototype; K. W. wrote the manuscript with support from X. J. L and Z. D. X; S. H. Y. contributed to the preparation of Fig.8; K. W. and M. Y. G conducted the experiment under the guidance of G. Z. and S. N. Z. All authors reviewed the manuscript.

\section{Funding}

National Key Research and Development Program of China (NKRDPC) (2017YFB0405204).

\section{Competing interests}

The authors declare no competing interests.

\section{Additional information}

Correspondence and requests for materials should be addressed to K. W. 
Figures

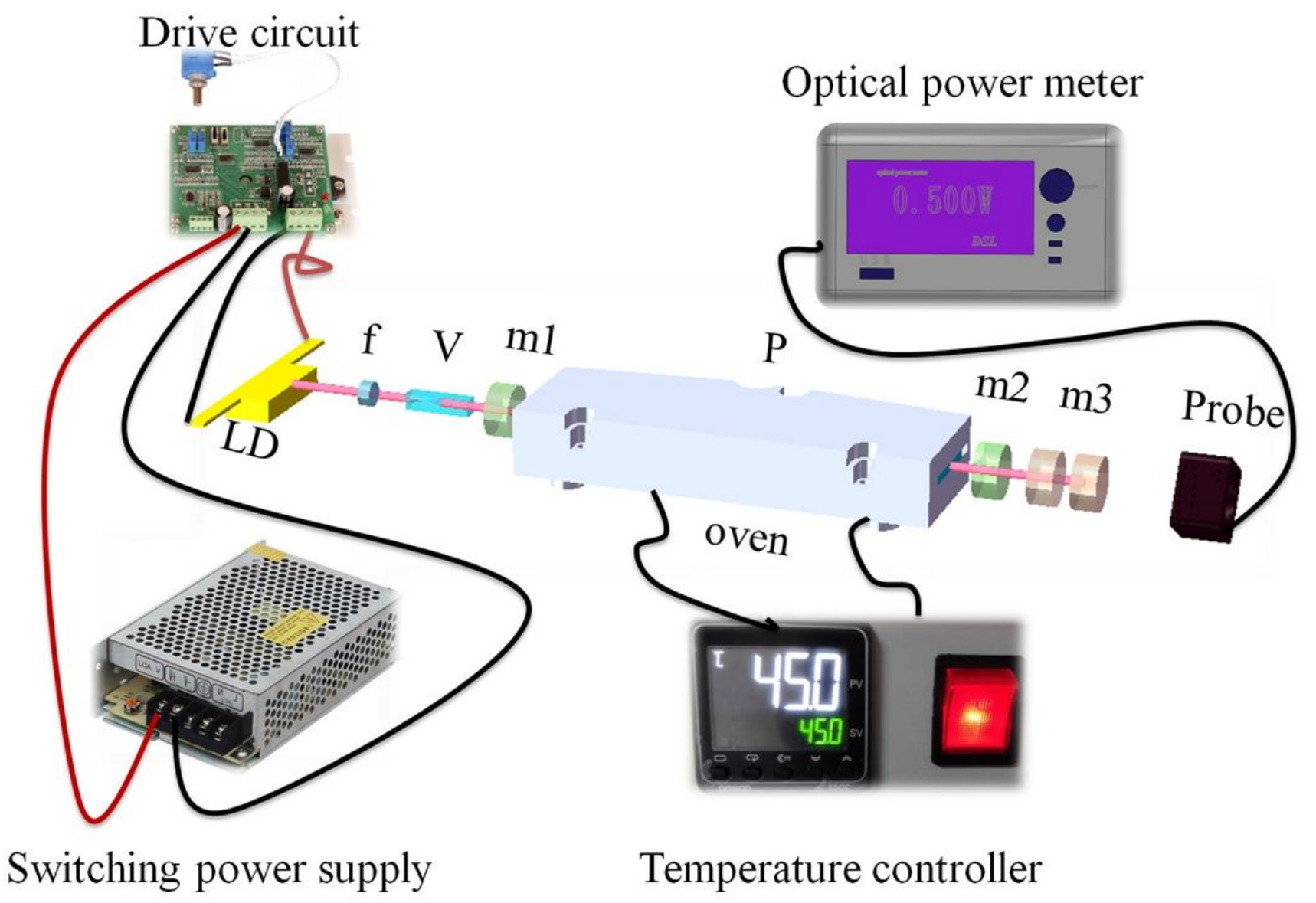

Figure 1

Experimental schematic diagram of IC-OPO. LD: solid $808 \mathrm{~nm}$ laser diode; $f$ : focusing lens; V: Nd:YVO4 crystal; m1: IC-OPO input mirror; P: PPLN crystal; m2: IC-OPO output mirror; m3: dichroic mirrors. 


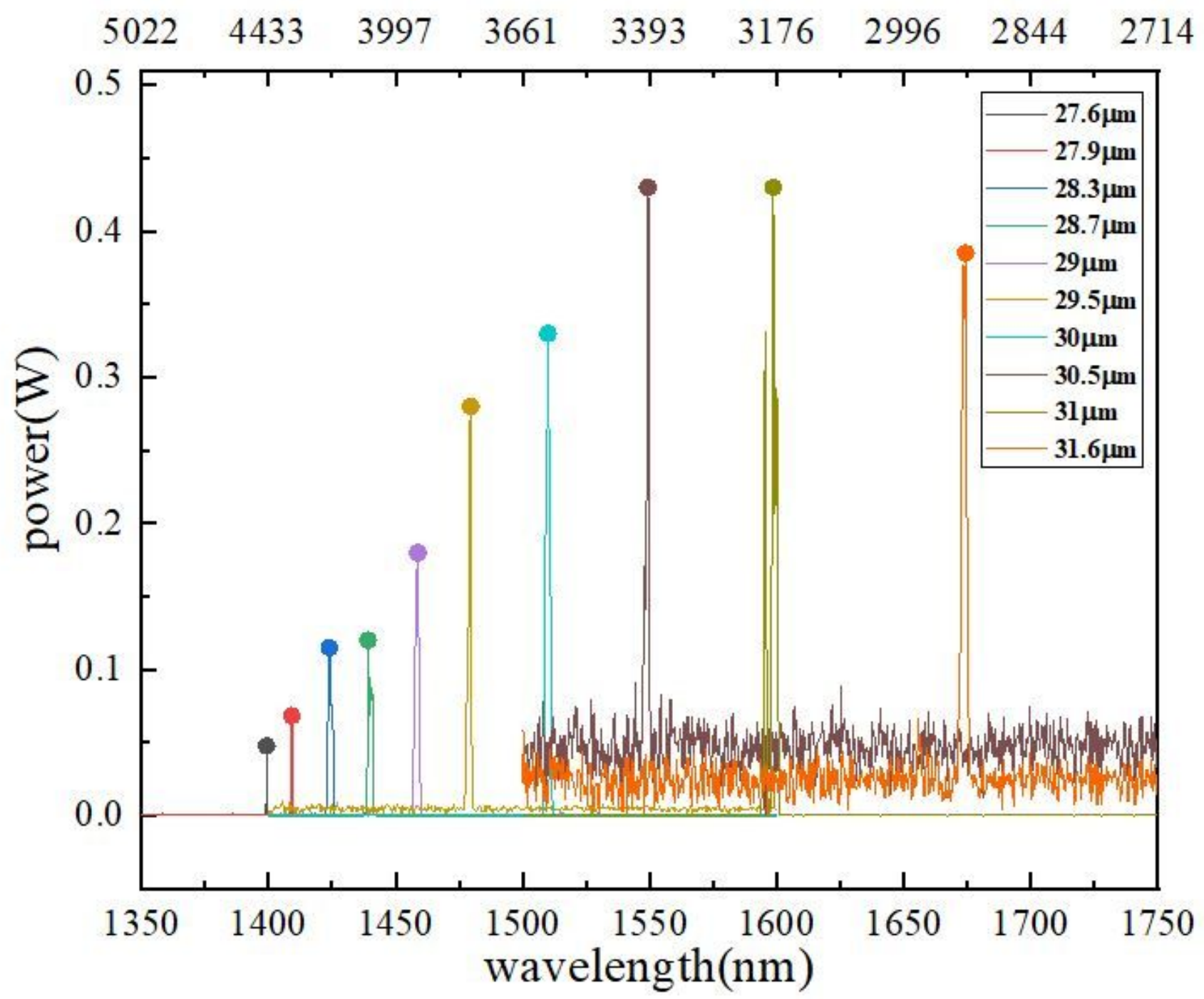

Figure 2

Signal wavelength of different channels at operating temperature of 40 \. Label of bottom axis means wavelength of signal while top line is corresponding calculated wavelength of idler and the $\mathrm{Y}$-axis is power of idler. 


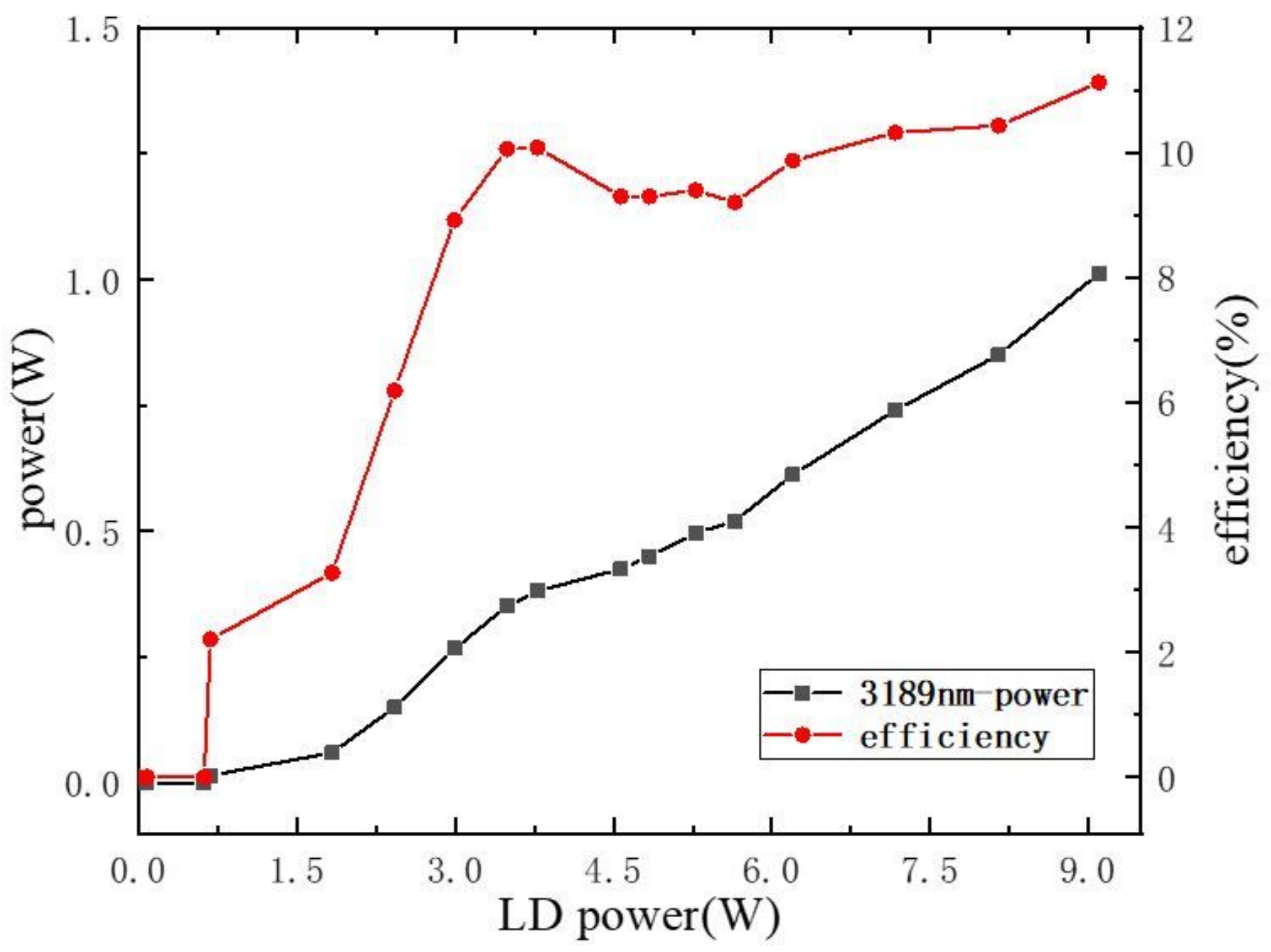

Figure 3

Output power and efficiency versus incident LD power. 


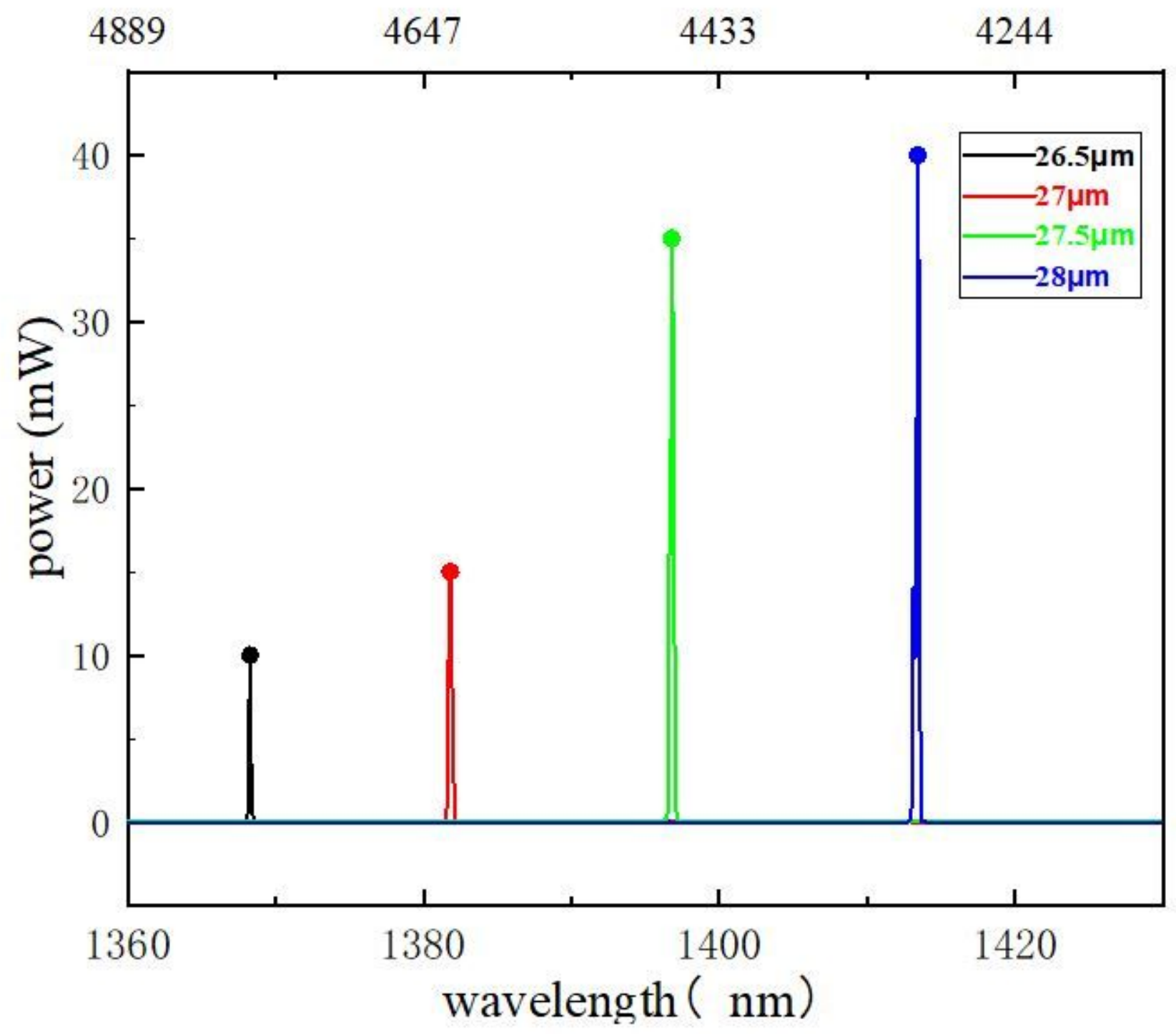

Figure 4

Signal wavelength of different channels at $45 \rrbracket$ when power is $4.84 \mathrm{~W}$. 


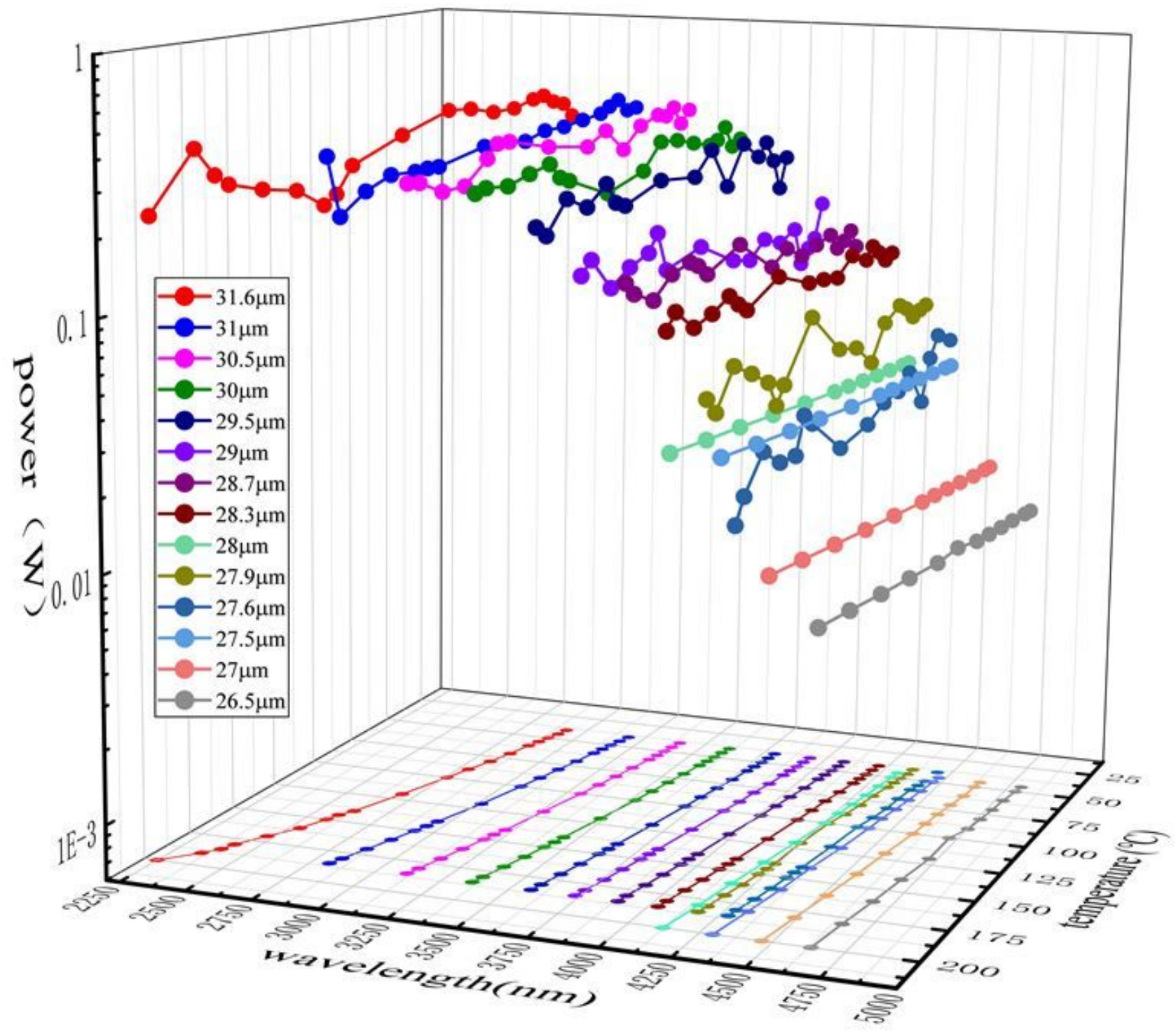

Figure 5

Curves of tuning temperature and periods. Span of idler is from $2.25 \mu \mathrm{m}$ to $4.79 \mu \mathrm{m}$ when pump power is $4.8 \mathrm{~W}$. 

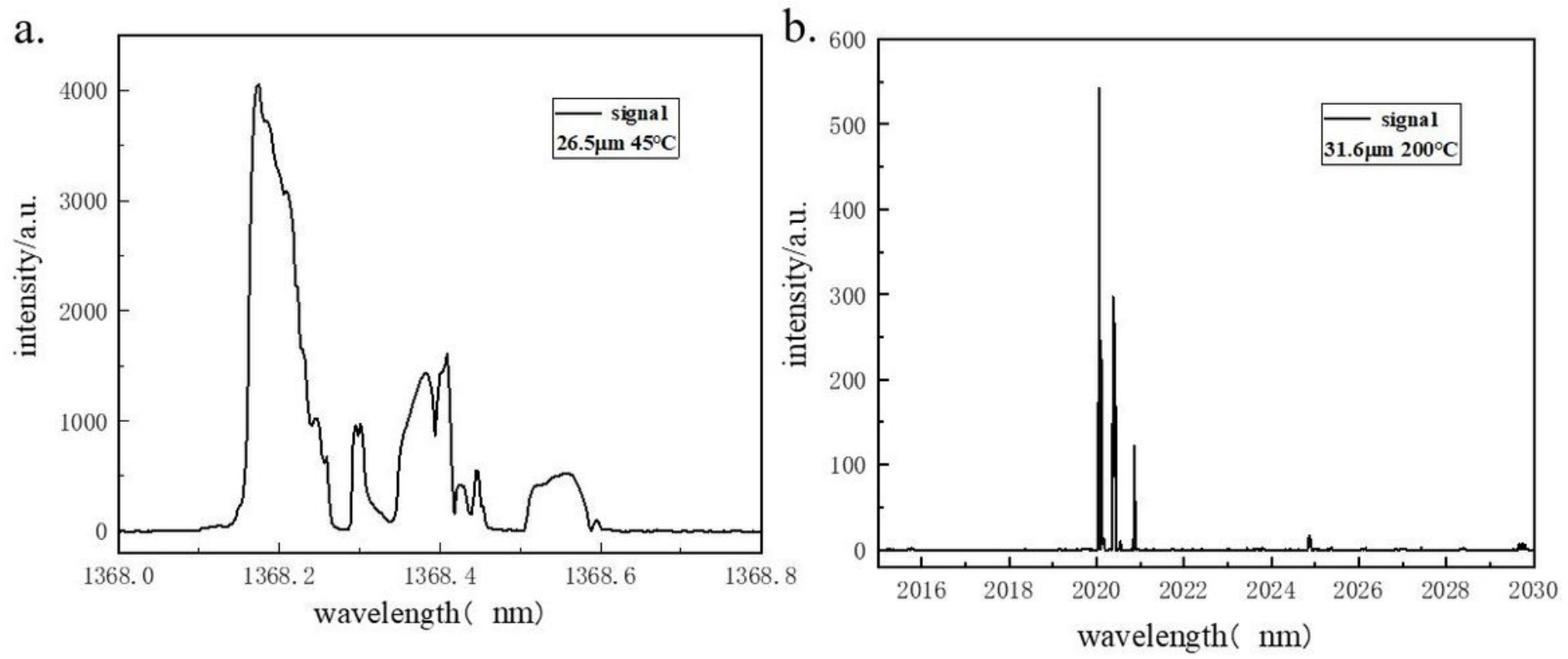

Figure 6

Shortest and longest signal spectra.
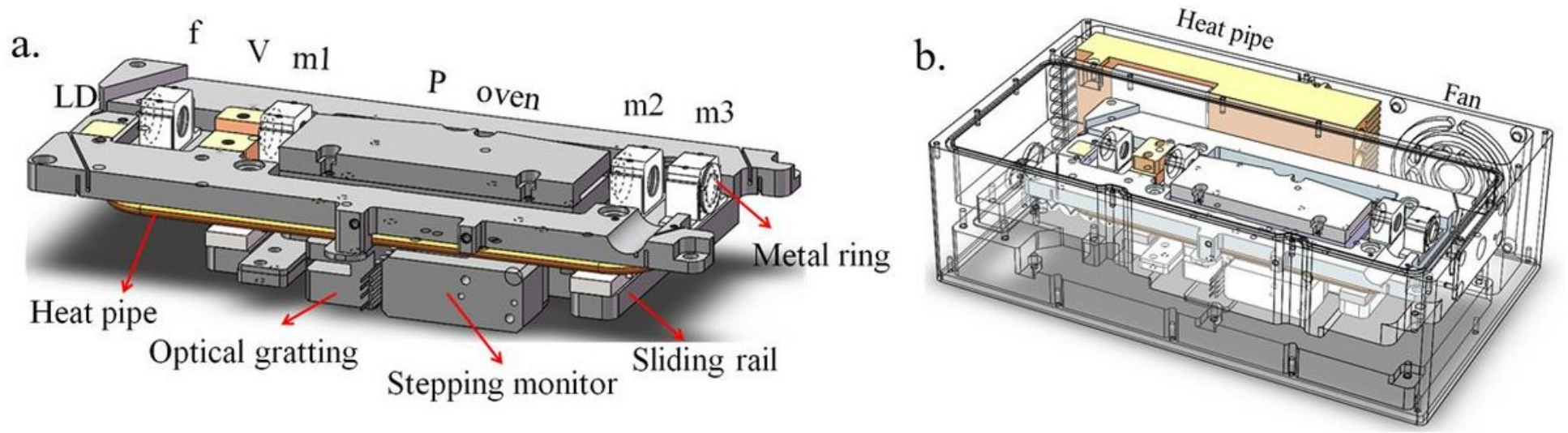

Figure 7

Design of the singly resonant IC-OPO prototype. 

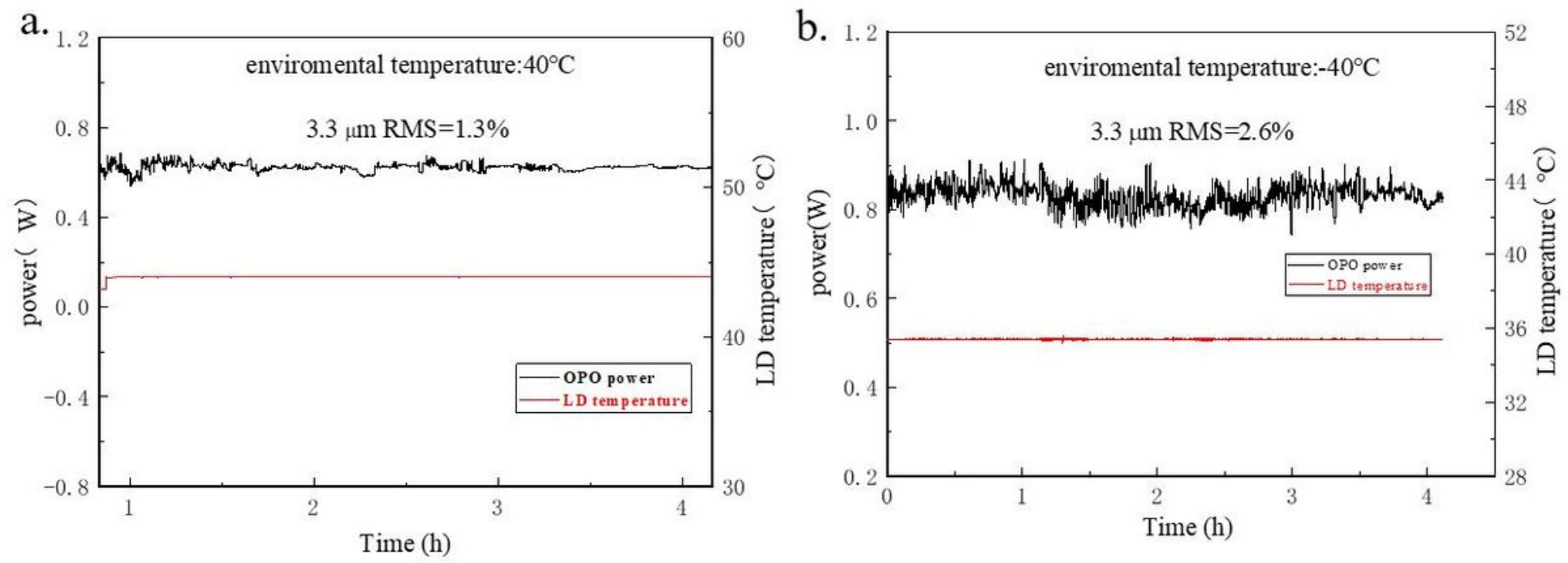

Figure 8

Results of test at low and high temperatures. 